\title{
Short-term Cost-effectiveness of Reteplase versus Primary Percutaneous Coronary Intervention in Patients with Acute STEMI a Tertiary Hospital in
} Iran

\author{
Khalil Alimohammadzadeh (PHD) ${ }^{1,2}$, Roxana Sadeghi (MD) \\ Ali Maher (PHD) ${ }^{4}$, Mohammad Kazem Kazemi (MS) ${ }^{1, *}$
}

${ }^{1}$ Department of Health Services Management, North Tehran Branch, Islamic Azad University, Tehran, Iran.

${ }^{2}$ Health Economics Policy Research Center, Tehran Medical Sciences Branch, Islamic Azad University, Tehran, Iran.

${ }^{3}$ Cardiovascular Research Center, School of Medicine, Shahid Beheshti University of Medical Sciences, Tehran, Iran.

${ }^{4}$ Department of Health Care Administration, North Tehran Branch, Islamic Azad University, Tehran, Iran

* Corresponding author: Mohammad Kazem Kazemi, Educating in Health Services Management, North Tehran Branch, Islamic Azad University, Tehran, Iran, Tel:

DOI: $10.21859 / \mathrm{ijcp}-020305$ +982177558090, Cell:09126725510.Email:mohamadkazemkazemi@yahoo.com

Submited: 04.25 .2017

Accepted: 06.10.2017

\section{Keywords:}

Primary percutaneous coronary intervention

Reteplase

Myocardial infarction

C) 2017. International Journal of Cardiovascular Practice.

\begin{abstract}
Introduction: This study aimed to compare primary percutaneous coronary intervention (PPCI) versus reteplase in terms of clinical and para-clinical outcomes; as well as costeffectiveness in patients with ST-segment-elevation myocardial infarction (STEMI). Primary percutaneous coronary intervention is the method of choice in all patients especially those at higher risks. But an on-site professional team in a $24 / 7$ facilitated system is a difficult goal to achieve in many areas and countries, therefore the cost-effectiveness of these two treatment strategies (PPCI and reteplase) needs to be discussed.

Methods: This prospective cohort study included 220 patients presented with STEMI who were admitted to a university hospital between January 2014 to July 2016. Patients were divided into two groups of 120, either receiving reteplase or PPCI. Clinical outcomes were considered duration of hospital stay and MACE (Major Advanced Cardiovascular Events) including death, cerebrovascular accident, need for repeat revascularization, and major bleeding. LVEF (Left ventricular ejection fraction) was considered as a para-clinical outcome. The outcomes and total hospital cost were compared between two treatment groups.

Results: Demographic characteristics between two groups of PPCI or reteplase didn't show any significant differences. But in para-clinical outcomes, patients in PPCI group showed higher LVEF, compared with reteplase group ( $45.9 \pm 11.5 \%$ versus $42.0 \pm 11.8 \%$; $\mathrm{P}=0.02$ ). Complication rates were similar in both groups but repeat revascularization or coronary artery bypass surgery was more prevalent in those who received thrombolytic therapy $(\mathrm{P}<0.05)$. Length of hospital stay in both groups was similar in two groups but total cost was higher in patients who have received PPCI. (147769406.9 \pm 103929358.9 Tomans vs. $117116656.9 \pm 67356122.6$ Tomans; respectively, $\mathrm{P}=0.01)$.

Conclusions: In STEMI patients who present during off-hours, thrombolytic therapy seems to represent a safe alternative to PPCI. Higher costs for patients with PPCI may be decreased with shorter duration of hospital stays according to guidelines.
\end{abstract}

\section{INTRODUCTION}

For prioritize and setting policies of health systems, the amount of available resources and their allotment way are among the main limiting factors. Given the high prevalence of heart disease, the impact of these two methods (reteplase and percutaneous coronary intervention) which are the main duties of director's treatment in patients with ST-segment-el- 
evation myocardial infarction (STEMI), were studied in Imam Hussein Hospital of Tehran. Nowadays, coronary artery disease is the first cause of death in most societies. Although the mortality from acute myocardial infarction has fallen about $30 \%$ over the past decade, approximately each year a million people are suffering from acute myocardial infarction in the United States of America. 1.2 million of the patients leads to death [1]. In our country cardiovascular disease is the top cause of mortality (46\% in 2001) [2]. Despite the great advances which have been happened in controlling and treatment of coronary artery diseases(CAD) in recent decades, it is predicted that by 2025 , mortality from cardiovascular disease surpass from other causes of mortality (cancer, trauma, etc.) and CAD will be the foremost causes of mortality. Percutaneous coronary intervention is a non-surgical method for treating narrowed blood vessels in coronary disease. Despite better clinical outcomes seen in the case of primary percutaneous coronary intervention (PPCI), in the majority of patients who do not have access to PPCI, thrombolytic therapy is offered as the selective treatment for reperfusion [3].

\section{METHODS}

This prospective observational study was conducted to determine short term cost-effectiveness of PPCI versus reteplase therapy in patients with STEMI. The study population included patients with the first episode of STEMI that became candidates for taking thrombolytic or PPCI treatment. In this study, the Acute STEMI patients who were older than eighteen years, involved in research out of all of the patients that admitted to the emergency room of Imam Hussein Hospital in Tehran. Acute STEMI indicator was the presence of typical angina for more than 30 minutes and less than 12 hours joint with STEMI electrocardiographic criteria based on the ACC / AHA guidelines. Patients were divided into two groups, one group received reteplase treatment and the second one underwent PPCI. These groups were compared in terms of the following indicators:

1) Demographic characteristics.

2) Clinical criteria for hospital stay.

3) Laboratory parameters, ECG, echocardiography and angiography.

4) Consequences of treatment, such as mortality, the occurrence of re-myocardial ischemia and the need for revascu- larization, ischemic or hemorrhagic cerebrovascular events, important hemorrhagic complications or need for blood transfusions and the need for emergency dialysis.

5) The total cost of the treatment from the time of admission to discharge, including medical direct costs (consumable equipment, personnel costs) and tariffs paid by patients, and hospital stay.

Information was entered to the questionnaires by the investigators and collaborator resident then was studied by statistical analysis. To use information of patients, written permission was obtained from patients or their legal attendants, and Medical Sciences Ethics Committee of Shahid Beheshti University approved the project. Data were gathered by using both direct interviews with patients and reviewing archived files.

\section{RESULTS}

In this study, 220 patients with acute myocardial infarction were studied between the years from 2015 to 2016. Inclusion criteria were the chest pain which consistent with acute myocardial infarction in the past twelve hours alongside ECG changes compatible with myocardial infarction based on ACC / AHA guidelines. Exclusion criteria were previous history of heart attack, coronary angioplasty or open heart surgery. The first group included 110 patients with acute myocardial infarction who underwent PPCI and the second group included 110 patients who were received reteplase. The average age for the first group was $61.2 \pm 11.2$ and for the second group which received reteplase was $58.6 \pm 12.2(\mathrm{P}>$ $0.05)$. The number of people over 75 years was equal in both groups and formed ten percent of the population. Gender distribution in the two groups of PPCI and reteplase has not statistically significant difference. The baseline characteristics of the patients are provided in Table 1.

Ischemic time in two groups of reteplase and PPCI was 6.0 \pm 10.5 and $3.8 \pm 5.5$, respectively $(P=0.08)$. There weren't any significant differences between two groups for clinical indicators of patients, laboratory tests and involved vessels at the time of presentation. However maximum troponin level was higher in the PPCI group $(\mathrm{P}=0.03)$. The left ventricular ejection fraction (LVEF) assessed with echocardiography at admission time was $45.9 \pm 11.5$ and $11.8 \pm 42.0$ in patients who underwent PPCI and received reteplase, respectively (Table 2, 3).

\begin{tabular}{|lccc|}
\hline \multicolumn{2}{|l|}{ Table 1: Demographic Indicators of Patients who Underwent PPCI or Received Reteplase } & & Reteplase (n= 110) \\
Age & PPCI $(\mathbf{n}=\mathbf{1 1 0})$ & $58.6 \pm 12.2$ & 0.105 \\
Age over 75 years & $61.2 \pm 11.2$ & $11(10 \%)$ & 1.000 \\
Sex (man) & $11(10 \%)$ & $82(74.5 \%)$ & 0.878 \\
Diabetes & $81(73.6 \%)$ & $32(29.1 \%)$ & 0.447 \\
hypertension & $27(24.5 \%)$ & $42(38.2 \%)$ & 0.492 \\
Smoker & $47(42.7 \%)$ & $44(40 \%)$ & 0.262 \\
Family history of coronary & $36(32.7 \%)$ & $14(12.7 \%)$ & 0.837 \\
History of coronary disease & $13(11.8 \%)$ & $10(9.1 \%)$ & 0.623 \\
History of stroke & $8(7.3 \%)$ & $1(0.9 \%)$ & 0.313 \\
\hline
\end{tabular}

Data in table are presented as No. (\%) or Mean \pm SD

Abbreviations: PPCI, primary percutaneous coronary intervention 


\begin{tabular}{|lccc|}
\hline Table 2: The baseline clinical indicators of patients who underwent PPCI or received Reteplase & & \\
& PPCI (n= 110) & Reteplase (n= 110) & Pvalue \\
Ischemic time (min) & $6.0 \pm 10.5$ & $3.8 \pm 5.5$ & 0.076 \\
Systolic blood pressure (mmHg) & $126.0 \pm 31.3$ & $130.6 \pm 30.6$ & 0.253 \\
Heart beats (per minutes) & $81.0 \pm 15.8$ & $78.6 \pm 16.5$ & 0.281 \\
Blood oxygen saturation & $94.4 \pm 4.2$ & $93.8 \pm 6.9$ & 0.577 \\
Pulmonary edema & $4(3.6 \%)$ & $3(2.7 \%)$ & 0.701 \\
Cardiogenic shock & $10(9.1 \%)$ & $8(7.3 \%)$ & 0.623 \\
\hline
\end{tabular}

Data in table are presented as No. (\%) or Mean \pm SD

Abbreviations: PPCI, primary percutaneous coronary intervention

\begin{tabular}{|c|c|c|c|}
\hline & PPCI $(n=110)$ & Reteplase $(n=110)$ & Pvalue \\
\hline Hemoglobin (mg / dL) & $13.3 \pm 1.7$ & $13.4 \pm 1.7$ & 0.627 \\
\hline White blood cell & $10129.2 \pm 9760.8$ & $9908.5 \pm 3518.6$ & 0.826 \\
\hline Platelets & $225343.8 \pm 64702.4$ & $247611.1 \pm 73214.0$ & 0.023 \\
\hline Creatinine (mg / dL) & $1.1 \pm 0.5$ & $1.1 \pm 0.3$ & 0.343 \\
\hline Fasting glucose (mg / dL) & $160.8 \pm 94.4$ & $160.6 \pm 88.9$ & 0.986 \\
\hline HbAlc & $6.7 \pm 1.5$ & $7.8 \pm 1.6$ & 0.042 \\
\hline Cholesterol (mg / dL) & $165.0 \pm 33.5$ & $173.9 \pm 43.7$ & 0.140 \\
\hline Triglycerides $(\mathrm{mg} / \mathrm{dL})$ & $116.7 \pm 50.0$ & $154.2 \pm 99.3$ & 0.007 \\
\hline $\mathbf{L D L}(\mathbf{m g} / \mathbf{d L})$ & $98.4 \pm 26.3$ & $102.7 \pm 29.5$ & 0.363 \\
\hline HDL (mg/dL) & $37.4 \pm 7.7$ & $38.7 \pm 8.8$ & 0.350 \\
\hline Primary CK-MB & $81.2 \pm 135.5$ & $56.9 \pm 98.3$ & 0.147 \\
\hline Maximum CK-MB & $184.2 \pm 160.7$ & $279.7 \pm 440.1$ & 0.108 \\
\hline Primary Troponin & $3.6 \pm 7.5$ & $1.8 \pm 6.5$ & 0.066 \\
\hline Maximum Troponin & $9.4 \pm 9.3$ & $14.5 \pm 11.4$ & 0.033 \\
\hline LVEF (\%) & $45.9 \pm 11.5$ & $42.0 \pm 11.8$ & 0.020 \\
\hline The number of involved vessels & $2.0 \pm 0.9$ & $2.0 \pm 1.0$ & 0.807 \\
\hline involved vessel & & & 0.173 \\
\hline $\mathrm{LAD}$ & $61(56 \%)$ & $25(59.5 \%)$ & \\
\hline LCX & $20(18.3 \%)$ & $2(4.8 \%)$ & \\
\hline RCA & $26(23.9 \%)$ & $14(13.3 \%)$ & \\
\hline
\end{tabular}

Data in table are presented as No. (\%) or Mean \pm SD

Abbreviations: PPCI, primary percutaneous coronary intervention; LDL, Low-Density Lipoprotein; HDL, High-Density Lipoprotein; CKMB, Creatinine Kinase-MB; LVEF = Left Ventricular Ejection Fraction; LAD = Left Anterior Descending Artery; LCX = Left Circumflex Artery; RCA = Right Coronary Artery.

\begin{tabular}{|lccc|}
\hline \multicolumn{4}{|l|}{ Table 4: Complications during Hospitalization of Patients who Underwent PPCI or Received Reteplase } \\
\hline PPCI $(\mathbf{n}=\mathbf{1 1 0})$ & Reteplase $(\mathbf{n = 1 1 0})$ & P value \\
Post treatment cardiac surgery & $5(4.5 \%)$ & $26(23.6 \%)$ & 0.000 \\
Providing balloon pump & $5(4.5 \%)$ & $3(2.7 \%)$ & 0.471 \\
Death & $8(7.3 \%)$ & $8(7.3 \%)$ & 1.000 \\
Gastrointestinal bleeding & $0(0 \%)$ & $2(1.8 \%)$ & 0.155 \\
Ischemic stroke & $3(2.7 \%)$ & $5(4.5 \%)$ & 0.471 \\
Hemorrhagic stroke & $0(0 \%)$ & $1(0.9 \%)$ & 0.316 \\
Post treatment ischemia & $0(0 \%)$ & $6(5.5 \%)$ & 0.013 \\
Reinfarction & $0(0 \%)$ & $2(1.8 \%)$ & 0.155 \\
\hline
\end{tabular}

Data in table are presented as No. (\%).

Abbreviations: PPCI, primary percutaneous coronary intervention 


\begin{tabular}{|c|c|c|c|}
\hline & PPCI $(n=110)$ & Reteplase $(\mathrm{n}=110)$ & Pvalue \\
\hline $\begin{array}{l}\text { The number of hospitaliza- } \\
\text { tion days }\end{array}$ & $8.4 \pm 7.1$ & $9.5 \pm 5.0$ & 0.183 \\
\hline Lack of insurance & $0(0 \%)$ & $7(6.5 \%)$ & 0.006 \\
\hline The total cost & $147769409.9 \pm 103929358.9$ & $117116656.9 \pm 67356122.6$ & 0.011 \\
\hline Labor costs & $15215405.2 \pm 39341931.4$ & $13169090.8 \pm 12103401.5$ & 0.608 \\
\hline Hoteling cost & $22786500 \pm 35164424.9$ & $22329299.1 \pm 18169809.4$ & 0.908 \\
\hline Basic insurance & $123073453.0 \pm 93184332.2$ & $91685226.5 \pm 58729318.6$ & 0.004 \\
\hline Subsidy & $10539829.7 \pm 11708477.0$ & $14431664.5 \pm 9518778.3$ & 0.009 \\
\hline Patient share & $11716821.4 \pm 21177154.6$ & $9751561.4 \pm 13471528.1$ & 0.420 \\
\hline
\end{tabular}

Data in table are presented as No. (\%) or Mean \pm SD

Abbreviations: PPCI, primary percutaneous coronary intervention

$4.5 \%$ and $23.6 \%$ of the groups that underwent PPCI and received reteplase respectively had open heart surgery during hospital stay $(\mathrm{P}=0.001)$. Generally, the probably of re-ischemic heart disease at hospital stay in reteplase group was higher than PPCI but myocardial infarction was not $(\mathrm{P}<0.05)$. Other complications during hospitalization including death, ischemic or hemorrhagic stroke, important bleeding such as gastrointestinal bleeding or the need for blood transfusions were similar between the two groups $(\mathrm{P}>0.05)$. Complications during hospitalization for each group were shown in Table 4.

The mean duration of hospitalization for the patients who received PPCI was $8.4 \pm 7.1$ and $9.5 \pm 5.0$ for the group receiving reteplase, which there was not statistically significant difference $(P>0.05)$. The total cost between the two groups showed statistically significant difference $(\mathrm{P}<$ 0.05); however, hoteling cost and manpower for PPCI and reteplase group were not statistically significant $(\mathrm{P}>0.05)$ (Table 5).

\section{DISCUSSION}

In patients with acute myocardial infarction who admitted to the hospital at the optimal time, superiority of PPCI is known compare to thrombolytic therapy [4]. However, all over the world providing environments for angiography for twenty-four hours a day and seven days a week is not possible. In many populated areas of the world, acute myocardial infarction is the first cause of death; thus high prevalence increases cost importance. In this study, patients' average age and sex were close to some other studies [5]. Both groups were similar in terms of demographic indicators; Differences of clinical indicators or laboratory finding were not statistically significant. It is high lighting the findings worth. The high number of patients in each group had no similar in other national studies and provide comparison of findings to similar great studies $[6,7]$. The most common vessel responsible for the infarction in both groups was left anterior descending artery and maximum number of involved vessels was one or two which absolutely was consistent with existing meta-analysis. The two treatments have not significant differences in terms of complications. There are studies that have reported complications of PPCI are less than thrombolytic, but the number of patients in these studies was higher, and the mean age of the patients in therapy groups for these research is variable [8]. The mortality in both groups was $7.3 \%$ and entirely was close to credible other studies [9].

There are many studies that indicated the high value of LVEF for the prognosis of patients. In this study, LVEF in PPCI group patients at the time of hospitalization was better than reteplase group [9]. Hospital stay duration was similar for both groups, but according to other similar studies, hospital stay was longer in PPCI group in our study which is the positive important point that can demonstrate the need for a clinical review $[10,11]$. The same hospital stay for both groups had been led to same Hoteling and Labor costs for reteplase and PPCI groups. However, ultimately higher consumable costs in PPCI increased significantly the total cost of PPCI rather than reteplase group. High cost of initial hospitalization for patients with acute myocardial infarction who received primary PCI has been shown in some similar studies, and the consumable costs and the number of need for re-hospitalizations differences should be proved in the longer studies [12-15]. This article only study the short term cost of PPCI and reteplase therapy in patients with STEMI in Iran, so, the results should not extend to the long term benefits of PPCI versus thrombolytic therapy.

Calculation of the cost and effectiveness of the two methods can be a key point for decision-making and policy, contributing to implement the most appropriate treatment strategy; therefore they can be used for strategic planning of the Ministry of Health in the long term.

\section{ACKNOWLEDGMENTS}

This article is extracted from a Health Care Management Master thesis of Mohammad Kazem Kazemi with the guild of Dr. Khalil Ali Mohammadzadeh and Dr. Ali Maher. This research was supported by Islamic Azad University (North Tehran Branch).

\section{AUTHORS' CONTRIBUTION}

Conception or design of the work: Sadeghi; Data collection: Kazemi; Data analysis and interpretation: Maher, Sadeghi; Drafting the article: Kazemi; Critical revision of the article:; Alimohammadzadeh; Final approval of the version to be published: Alimohammadzadeh 


\section{CONFLICTS OF INTERESTS}

The authors of this article declared no conflicts of interest.

\section{REFERENCES}

1. Liu JL, Maniadakis N, Gray A, Rayner M. The economic burden of coronary heart disease in the UK. Heart. 2002;88(6):597-603. PMID: 12433888

2. Azizi F, Rahmani M, Emami H, Mirmiran P, Hajipour R, Madjid $\mathrm{M}$, et al. Cardiovascular risk factors in an Iranian urban population: Tehran lipid and glucose study (phase 1). Soz Praventivmed. 2002;47(6):408-26. PMID: 12643001

3. Llevadot J, Giugliano RP, Antman EM. Bolus fibrinolytic therapy in acute myocardial infarction. Jama. 2001;286(4):442-9.

4. Keeley EC, Boura JA, Grines CL. Primary angioplasty versus intravenous thrombolytic therapy for acute myocardial infarction: a quantitative review of 23 randomised trials. Lancet. 2003;361(9351):1320. DOI: 10.1016/S0140-6736(03)12113-7 PMID: 12517460

5. Gibson CM. Primary angioplasty compared with thrombolysis: new issues in the era of glycoprotein IIb/IIIa inhibition and intracoronary stenting. Ann Intern Med. 1999;130(10):841-7. PMID: 10366375

6. Grines CL, Browne KF, Marco J, Rothbaum D, Stone GW, O’Keefe $\mathrm{J}$, et al. A comparison of immediate angioplasty with thrombolytic therapy for acute myocardial infarction. The Primary Angioplasty in Myocardial Infarction Study Group. N Engl J Med. 1993;328(10):673-9. DOI: 10.1056/NEJM199303113281001 PMID: 8433725

7. Andersen HR, Nielsen TT, Rasmussen K, Thuesen L, Kelbaek H, Thayssen $\mathrm{P}$, et al. A comparison of coronary angioplasty with fibrinolytic therapy in acute myocardial infarction. N Engl J Med. 2003;349(8):733-42. DOI: 10.1056/NEJMoa025142 PMID: 12930925

8. Zahn R, Schiele R, Schneider S, Gitt AK, Wienbergen H, Seidl K, et al. Decreasing hospital mortality between 1994 and 1998 in patients with acute myocardial infarction treated with primary angioplasty but not in patients treated with intravenous thrombolysis. Results from the pooled data of the Maximal Individual Therapy in Acute Myocardial Infarction (MITRA) Registry and the Myocardial Infarction Registry (MIR). J Am Coll Cardiol. 2000;36(7):2064-71. PMID: 11127442

9. Grines C. Senior Primary Angioplasty in Myocardial Infarction - 30 Day Results. Transcatheter Cardiovascular Therapeutics Conference; Washington DC2005.

10. Boersma E, Primary Coronary Angioplasty vs. Thrombolysis G. Does time matter? A pooled analysis of randomized clinical trials comparing primary percutaneous coronary intervention and in-hospital fibrinolysis in acute myocardial infarction patients. Eur Heart J. 2006;27(7):779-88. DOI: 10.1093/eurheartj/ehi810 PMID: 16513663

11. Cohen DJ, Taira DA, Berezin R, Cox DA, Morice MC, Stone GW, et al. Cost-effectiveness of coronary stenting in acute myocardial infarction: results from the stent primary angioplasty in myocardial infarction (stent-PAMI) trial. Circulation. 2001;104(25):3039-45. PMID: 11748097

12. Le May MR, Davies RF, Labinaz M, Sherrard H, Marquis JF, Laramee LA, et al. Hospitalization costs of primary stenting versus thrombolysis in acute myocardial infarction: cost analysis of the Canadian STAT Study. Circulation. 2003;108(21):2624-30. DOI: 10.1161/01.CIR.0000097120.26062.FE PMID: 14597591

13. Morgan KP, Leahy MG, Butts JN, Beatt KJ. The cost effectiveness of primary angioplasty compared to thrombolysis in the real world: one year results from West London. EuroIntervention. 2010;6(5):596603. DOI: 10.4244/EIJV6I5A100 PMID: 21044913

14. Bravo Vergel Y, Palmer S, Asseburg C, Fenwick E, de Belder M, Abrams $\mathrm{K}$, et al. Is primary angioplasty cost effective in the UK? Results of a comprehensive decision analysis. Heart. 2007;93(10):123843. DOI: $10.1136 /$ hrt.2006.111401 PMID: 17717037

15. Wailoo A, Goodacre S, Sampson F, Alava MH, Asseburg C, Palmer S, et al. Primary angioplasty versus thrombolysis for acute ST-elevation myocardial infarction: an economic analysis of the National Infarct Angioplasty project. Heart. 2010;96(9):668-72. DOI: 10.1136/ hrt.2009.167130 PMID: 19508972 